\title{
The Impact of Application of Electronic Portfolio on Undergraduate English Majors' Writing Proficiency and their Self-Regulated Learning
}

\author{
Samaneh Karami \\ Department of English Language, Shiraz Branch, Islamic Azad University, Shiraz, Iran, \\ samaneh.karami88@gmail.com
}

\section{Firooz Sadighi}

Department of English Language, Shiraz Branch, Islamic Azad University, Shiraz, Iran,firoozsadighi@yahoo.com

\section{Mohammad Sadegh Bagheri}

Department of English Language, Shiraz Branch, Islamic Azad University, Shiraz, Iran,bagheries@gmail.com

\section{Mohammad Javad Riasati}

Department of English Language, Shiraz Branch, Islamic Azad University, Shiraz, Iran,mjriasati2002@yahoo.com

The role of technology in educational settings all around the world has changed the methods of teaching and assessment in the last few decades. Unfortunately, the shortcomings of e-learning in Iran have deprived students of many advantages of it. This research paper tries to answer the questions regarding the effect of e-portfolio on the students' writing proficiency in the context of learning English as a foreign language and the learners' use of self-regulated learning strategies. Furthermore, the attitude of students towards the use of e-portfolio in the writing class was investigated based on the data obtained through the survey, teacher's field notes, and teachers' observations. The data obtained from English majors at State and Azad Universities in Rasht, north of Iran, was both qualitatively and quantitatively analysed. The findings revealed that the use of e-portfolio had a significant effect on students' writing proficiency and their use of self-regulated strategies. The evidence from the study also showed learners' positive attitude towards the use of e-portfolio, mainly due to its accessibility, convenience, and the feedback they could receive through it.

Keywords: e-portfolio, writing proficiency, self-regulated learning strategies, EFL context, assessment

Citation: Karami, S., Sadighi, F., Bagheri, M. S. \& Riasati, M. J. (2019). The Impact of Application of Electronic Portfolio on Undergraduate English Majors' Writing Proficiency and their Self-Regulated Learning. International Journal of Instruction, 12(1), 1319-1334. https://doi.org/10.29333/iji.2019.12184a 


\section{INTRODUCTION}

The effect of technology as an undeniable fact in educational settings in various fields cannot be ignored. Consequently, it is required to engage learners in activities which can be integrated into methodologies used in learning environments in order to increase learning, teaching and assessment outcomes. Electronic portfolios are known as one of the most remarkable developments in the field of language learning which is also in line with student-centered approaches.

In the context of this study, Iran, these technologies have not quite found their ways into language learning classes in general and universities in particular. The current situation requires teachers to enhance their technology proficiency, and one way to meet this challenge appears to lie in the use of electronic portfolios (EPs). An electronic portfolio provides learners with a chance to practice language skills and use of technology simultaneously. Several studies (Avraamidou \& Zembal- Saul, 2002; Woodward \& Nanlohy, 2004; Hirvela \& Sweetland, 2005) have indicated the advantages of eportfolios.

Furthermore, according to Arnold and Brown (1999), the recognition, identification, and improvements of affective variables and learning strategies need to be emphasized if learners are to become effective performers and/or active participants in the teaching-learning process. Self-regulated learning strategies are one of the effective variables in improving learners' performance. In a university educational system, students are expected to be self-regulated in their learning (Perry \& Vandekamp, 2000). Students who are self-regulated are meta-cognitively, motivationally, and behaviorally active participants in their own learning process (Zimmerman, 1989, p. 329) and thus succeed in academic learning (Rogers \& Swan, 2004). Unfortunately, only a few students have developed a high level of self- regulation of learning due to the fact that traditional teaching practices have been doing little to promote self-regulated learning (Zimmerman \& Risenberg, 1997).

Applying traditional methods of teaching and assessment in writing classes in Iran could not satisfy the needs of learners in a modern world. The underlying reason for students' dissatisfaction can be traced back to the unique nature of the traditional method of assessment. On the other hand, the extensive use of the alternatives in assessment (such as portfolios, writing journals or diaries) made it inevitable for teachers and researchers to try to take some advantage of such options in Iran. The result could be observed in the growing number of research which has been conducted in the field (for example, Firoozzare, 2006; Nezakatgoo, 2005; Heidari, 2009).

It has been observed that writing classes in most universities in Iran are run through conventional methods of assessment with the teacher assigning a topic for the students and then grading their papers and giving them back to the students who may not even take a look at the documents, let alone correct their mistakes (Pezeshki, 2010).

This study specifically focuses on the effect of e-portfolio in conjunction with two other variables, which are writing proficiency and self-regulated learning strategies; unlike 
previous studies which have never concentrated on these three specific variables all together at the same time in an EFL context.

The purpose of conducting this research is two-pronged. Firstly, this study aims at exploring the effect of implementing e-portfolios as an alternative method of assessment as opposed to the conventional method of teaching writing in EFL writing classrooms at a university in Iran on learners' writing proficiency. Secondly, it is intended to provide insight into the effect of e-portfolios on students' use of self-regulated learning strategies.

The following three research questions were guiding the aims of this study to check the probable effectiveness of an e-portfolio:

1. Does e-portfolio assessment enhance students' writing proficiency in the EFL context?

2. Does the application of e-portfolio enhance learners' use of self-regulated learning strategies?

3. What are the attitudes of students towards the use of e-portfolio in writing the class (based on a survey, teacher's field notes, and teacher's observations)?

\section{REVIEW OF LITERATURE}

\section{Writing and Electronic portfolios}

Muslimi (2015) mentions that portfolios have gained popularity among the educators and language teachers as an alternative approach both in EFL and in ESL contexts as an instructional tool for preparation of students for examinations. Portfolios are normally made of drafts and redrafts of students' writing and so can be of great help to the teachers because they enable them to watch their students' progress (Zhang, 2009). Ali (2005) also defines e-portfolios as a collection of students' works either online or on a CD-Rom which helps them share their function with a larger number of audiences, and at the same time motivating them and teaching them the language better. Many studies provide evidence that when students revise their papers after receiving feedback; their accuracy improves, either in the short or long term (Chandler, 2000; Ferris \& Helt, 2000; Lalande, 1982). E-portfolios of writing are "a mechanism for bringing together samples of learners ${ }^{\text {ce }}$ written work, thereby encouraging more global self-assessment of students' language skills" (Godwin-Jones, 2008). Anson (2000) believes the use of computers in educational contexts could bring about so many opportunities for change in the way teachers respond to the students ${ }^{\text {ee }}$ writing papers since electronic data supplanted "papers" and "written responses" (Anson, 2000).

\section{Writing and Self-regulated Learning}

Zimmerman's (2000) defines self-regulated learning by putting emphasis on the interaction of three major elements: (a) personal regulation, which refers to the adjustment of cognitive and affective factors, (b) behavioural self-regulation that mainly takes into account the process of observing oneself and modifying performance, and (c) 
environmental self-regulation that involves analyzing learning context, and making adaptations in a way that optimizes performance. The interactions of these components, according to Zimmerman (2000), occur in the forethought of task, performance, and self-reflection (stages of self-regulation). By adopting Zimmerman's theoretical perspective on self-regulated learning, this study has encompassed a broader perspective of the learner by including metacognitive, behavioral and socio-environmental factors. In a similar vein, some scholars have focused on the teachers and how SRL can be useful for them (Paris \& Winograd, 2001). Recently, some studies have been conducted that aimed to incorporate the role of Information and Communication Technologies (ICT) in SRL. For example, research on SRL in computer-supported collaborative learning environments (Kayashima \& Inaba, 2003), research on SRL through discourse analysis of teachers scaffolding students using a computer-based learning environment (Levin et al., 2004), and studies in blended learning contexts (Lynch \& Dembo, 2004).

\section{METHOD}

\section{Research Design}

This study employed a mixed methods design, since it was both qualitative and quantitative in nature, through the adopting a quasi-experimental design alongside with qualitative analysis of researcher's field notes and observation. Also, the students' performances in writing were described in terms of task response, coherence and cohesion, lexical resource, grammatical range and accuracy. Their performances were compared with the control group to see the amount of students' improvement over the period. The design was also qualitative in that students' growth over time was described through the e-portfolio they prepared (pre-test, post-test, control group design). The data collection process was based upon a 16-session quasi-experimental study (90 minutes for each session) in both experimental and control groups. Also, all the responses of the participants to the questionnaire and results were analyzed using the Statistical Package for Social Sciences (SPSS) version 17.0.

\section{Participants}

The participants of this study were 143 male and female students who were studying English language at both State and Azad Universities in Rasht, Guilan province, Iran, with different cultural background but the same native language. The students' ages ranged from 19 to 38, with the average of 21 and they were full-time students and had to take the Advanced Writing Course for two hours per week. Due to practical limitations, the researcher could not choose a random selection procedure. As a result, the convenience sampling method was employed which is probably the most common of all sampling techniques, in which intact classes are used.

\section{Instruments}

\section{Placement Test}

First of all, in order to ensure the homogeneity of the subjects regarding language proficiency, an Oxford Placement Test (Allan, 2004) was administered to them at the beginning of the first session of the class. After evaluating the responses, all the extreme 
scores were excluded from the study. The researcher then was sure that all the participants who were included in the study were at the same level of English language proficiency at the beginning of the study.

Pre-test and Post-test Writing

In order to measure the participants' level of writing proficiency, an IELTS topic was chosen and the students were asked to write an essay of maximum 250 words based on the topic. The same topic has been given to them 16 weeks later, in the last session of the class. The samples were rated based on the IELTS 9-band scoring system which is used to measure and report scores in a consistent manner.

In order to rate the students' writing samples, Academic IELTS writing assessment rubric was used. Based on the rubric, examiners used detailed performance descriptors when assessing the writing samples. Furthermore, the feedback the students received was based on the categories of this scale (task response, coherence, and cohesion, lexical resource, grammatical range and accuracy) since it provides the teacher with a mechanism based on which feedback can be provided as opposed to a holistic type of scoring (Hyland, 2003).

\section{Open-ended Questions}

In the present study, the "Electronic Portfolio Survey" by Abrami and Aslan (2007) was used to collect feedback from students' experience using e-portfolio. Learners' responses to open-ended questions later helped in analyzing the results obtained, especially regarding learners' attitude towards e-portfolio and the underlying reasons explaining the difference between the experimental and control groups.

\section{Edmodo}

Edmodo is a web page which can be used for educational purposes with the advantage it provides the members in letting every member of the group make changes on it. An account on Edmodo was made by the lecturer/researcher and then the link was shared with the students in e-portfolio group (experimental group), so they could join the website. The lecturer could assign and grade work on Edmodo and students could get help from the entire class on Edmodo. Furthermore, it is a safe environment.

\section{SRL Questionnaire}

The Student Learning Strategies Questionnaire (SLSQ) (Abrami \& Aslan, 2007) was administered to students both in experimental and control group at the end of the semester. It contains 20 Likert scale items to measure students' perception of their ability to employ SRL strategies including their ability to set learning goals, observe and correct their performance and reflect on the learning outcome. The SLSQ contains six scales, namely, goal setting, strategy planning, self-observation, self-instruction, feedback from adults, and self-evaluation. In the SLSQ, participants will rate themselves on each item using a five-point Likert scale ranging from "strongly agree" (1) to "strongly agree" (5). 


\section{Validity and Reliability of Instruments}

In order to maintain and check both the validity and reliability of instruments, different measures were taken. Triangulation of instruments plays a great role in ensuring the validity of the tools, so various methods were used to triangulate the instruments. For instance, the results which were obtained from the researchers observations and field notes, the pre-test post-test results and the data obtained from the SRL questionnaire were found to be similar, which in turn represent the validity of the instruments applied in the study.

Furthermore, a mixed methods approach was used which helps both reliability and validity of the study. Statistical methods were also applied to check the reliability of each of the scaled used in the research.

To ensure the reliability of the scores the students received based on the scale, two raters scored the students' papers on the pre-test. The scores were checked for inter-rater reliability. The correlation coefficient between the raters was checked, which was .82; that was high enough (Hyland, 2003, p. 217) to ensure inter-rater reliability. In the view of this positive result, and because of the practicality issue (lack of time), the rest of the papers during the treatment were assessed by the researcher alone. Besides, the reliability of the SRL questionnaire was calculated on the basis of total scores obtained and found to be 92 .

\section{Research Procedure}

The participants in the experimental group wrote about different topics in their textbooks (just the pre-test and post-test were chosen among IELTS writing topics, Task 2). Having received the participants' first drafts, the instructor (i.e., the researcher) read them carefully and wrote her comments based on the IELTS writing scoring rubrics in the website which had been developed. Each student could individually log into his/her account, see the comments of the instructor, the final grade he/she received, and also ask any questions they had regarding the assignment. Moreover, the students were able to consult with their teacher to have her comments in one-to-one conferencing during the class. They were also asked to have peer assessment, self-assessment or reflect on their writing in the classroom and evaluate their strengths and weaknesses in the website. Then, at home, the students revised, edited and rewrote their texts in response to peer and teacher feedback which were posted on the website. At the end of the term, the participants were asked to choose their three best writings for final evaluation. The writings of the participants were rated on a 9-band scale, in line with the IELTS writing scoring method.

The control group followed a traditional assessment. The teacher explained the writing structure of every lesson explicitly. In this group, students were asked to write their first and last text for getting a mark. In contrast to the experimental group, the students had no chance to edit or rewrite their texts into better ones. In the last session of the class, the researcher administered a questionnaire to find out their use of self-regulated learning strategies. 
Participants' comments on their weekly reflection (both self and peer-assessment of their writings), comments on the samples of writing in their e-portfolios, the teacher/researcher's monthly journal and her field notes provide the data for qualitative analyses.

\section{Data Analyses}

\section{Analyses of Quantitate Data}

The responses of the participants to the questionnaire were analyzed descriptively using the Statistical Package for Social Sciences (SPSS) version 17.0. The descriptive results include means and standard deviations to indicate the level of use of self-regulated learning in learners in both experimental and control groups. Questionnaire data were analyzed to obtain a fine-grained analysis of specific changes in self-regulation that occurred as a result of using e-portfolio or the conventional method.

After the administration of the post-test in the two groups, appropriate tests were used to answer the research questions. In order to answer the research questions posed at the beginning of the study (i.e. if there is any effect of teaching modes-e-portfolios or conventional - on students' writing proficiency), a One-Way ANOVA procedure was used to compare the means of the two groups before the implementation of the treatment. After the experiment, another One-Way ANOVA was used to examine the possible effect of the two modes of teaching writing (through e-portfolios and conventional mode). Also to examine whether the students' writing improved as a result of any of the two methods (e-portfolios or conventional classes), two paired t-tests were used, using each group's pre-test and post-test scores. All data were fed in the SPSS 17 to arrive at the results.

The study initially employed descriptive statistics in order to measure the learners' use of SLR strategies. Finally, in order to find out the learners' attitude towards implementing e-portfolio in the writing class, their answers were categorized and coded and the most recurring themes were recognized. A content analysis involves identifying, coding, categorizing, classifying and labelling the primary patterns/occurring themes in the data (Miles \& Huberman, 1994; Patton, 2002).

\section{Analyses of Qualitative Data}

Finally, in order to find out learners' attitude towards implementing e-portfolio in the writing class, their answers were categorized and coded and the most recurring themes were recognized. Content analysis involves identifying, coding, categorizing, classifying and labelling the primary patterns/occurring themes in the data (Miles \& Huberman, 1994; Patton, 2002). 


\section{FINDINGS}

\section{Quantitative Data: Analysis of the Difference between the Experimental and Control Group}

In order to choose a test, the researcher needs to decide whether parametric or nonparametric tests fit his/her data the best. The Kolmogorov-Smirnov test caters for the normality of the distribution. The K_S test was taken and the significance level obtained from K-S test for the research variables is more than the specified value of 0.05 . This means the two groups have normal distributions.

Afterwards, in order to compare the changes in students' writings in the experimental group and the control group based on the results of their post-test, independent t-test procedure was used. The results of the analyses are reported below in Table 1.

Table 1

Independent t-test between Post-tests of the Control and Experimental Groups

\begin{tabular}{|c|c|c|c|c|c|}
\hline Variables & $\begin{array}{l}\text { Level } \\
\text { significance }\end{array}$ & $\mathrm{T}$ & $\begin{array}{l}\text { Df. } \\
\text { Mean }\end{array}$ & $\begin{array}{l}\text { Mean } \\
\text { Pre-test }\end{array}$ & Mean Post-test \\
\hline Total & $\begin{array}{l}. / 000 \\
16 / 93\end{array}$ & & $-1 / 55$ & 8.32 & 6.76 \\
\hline
\end{tabular}

The results indicate that the mean score of the control group was 6.76 and the mean score of the experimental group was 8.32 in the post-test. It is clear that the learners had received higher scores in the experimental group. Also, the results of independent $t$ test between the control and experimental groups reveal that there is a significant difference between the means of the two groups in general $(\mathrm{P}=0.000)$.

\section{Results of Students' SRL Questionnaire}

An attempt was made to analyze the changes in the students' use self- regulated learning strategies in the control group (conventional method) and the experimental group (Eportfolio assessment). Table 2 and Table 3 represent the results obtained from the analysis of Self-regulated Learning Questionnaire given to the control and experimental groups. As indicated in this table, the mean score of the control group equals 3.41. Furthermore, the lowest score obtained was 1 and the highest score was 4.50 on a 5point Likert scale.

Table 2

Descriptive Statistics of SRL Questionnaire of Control Group

\begin{tabular}{llllllc}
\hline & $\mathrm{N}$ & Minimum & Maximum & Mean & Std. Deviation & Variance \\
\hline Control Group & 67 & 1.00 & 4.50 & 3.41 & .759 & .577 \\
\hline Valid N (listwise) & 67 & & & & & \\
\hline
\end{tabular}

Table 3 represents the results obtained from analysis of Self-regulated Learning Questionnaire which has been given to the experimental group. As shown in this table, the mean score of the control group is 3.74 . 
Table 3

Descriptive Statistics of SRL Questionnaire of Experimental Group

\begin{tabular}{llllccc}
\hline & $\mathrm{N}$ & Minimum & Maximum & Mean & Std. Deviation & Variance \\
\hline Control Group & 84 & 3.00 & 5.00 & 3.7373 & .41166 & .169 \\
\hline Valid N (listwise) & 84 & & & & & \\
\hline
\end{tabular}

Finally, in order to compare the results of SRL questionnaire obtained from the control and the experimental groups, an independent t-test procedure was used. The results are shown in Table.4.

Table 4

Independent t-test between Results of SRL Questionnaire of the Control and Experimental Groups

\begin{tabular}{lllllc}
\hline Variables & $\begin{array}{l}\text { Level } \\
\text { significance }\end{array}$ & $\mathrm{T}$ & $\begin{array}{l}\text { Df. } \\
\text { Mean }\end{array}$ & $\begin{array}{l}\text { Mean } \\
\text { Pre-test }\end{array}$ & Mean Post-test \\
\hline Total & 0.002 & 3.12 & 0.31 & 3.73 & 3.41 \\
\hline
\end{tabular}

The results indicate that the mean score of the control group was 3.41 and the mean score of the experimental group was 3.73 in the SRL questionnaire. It is clear that the learners had received higher mean scores in the experimental group. Also, the results of the independent $t$ test between the control and experimental groups reveal that there is a significant difference between the means of the two groups in general $(\mathrm{P}=0.002)$.

\section{Analysis of the Qualitative Data}

The learners' answers to open-ended questions, contained in Electronic Portfolio Survey by Abrami and Aslan (2007) were put under three general categories: positive, negative and neutral. After analyzing the answers, using content analyses method through coding the written responses, it was found that $99 \%$ of the learners had either positive or negative attitudes, so the last category (neutral) was omitted. The results are presented in the following table.

Table 5

Learners' Attitudes towards E-portfolio

\begin{tabular}{lcc}
\hline Attitude towards E-portfolio & Number & Percentage \\
\hline Positive & 65 & $77.4 \%$ \\
\hline Negative & 19 & $22.6 \%$ \\
\hline Total & 84 & $100 \%$ \\
\hline
\end{tabular}

The percentages for the responses in this category indicate that $77 \%$ of the learners had positive attitudes towards implementation of EP in their writing class, while the other $23 \%$ hold a negative attitude towards it. The next step was analyzing their answers to find out why they hold either positive or negative attitudes and the underlying factors related to their experience.

\section{Learners' Positive Attitudes towards E-portfolio}

During this study, the learners were asked to describe their perceptions of e-portfolios as a process of learning and assessment technology. The students were supposed to answer whether they liked using e-portfolios and why. Their answers were analyzed then 
through coding process. A code in qualitative inquiry is most often a word or short phrase that symbolically assigns a summative, salient, essence capturing, and/or evocative attribute for a portion of language-based or visual data (Saldana, 2013).

As a result, the researcher started coding learners' answers to open-ended questions by first reading through them, and then generating general categories. These categories were then tested against the rest of the data, and sub-categories were created. After double-checking the all the categories and coding them, it was realized that their answers fall into one of the four categories mentioned below:

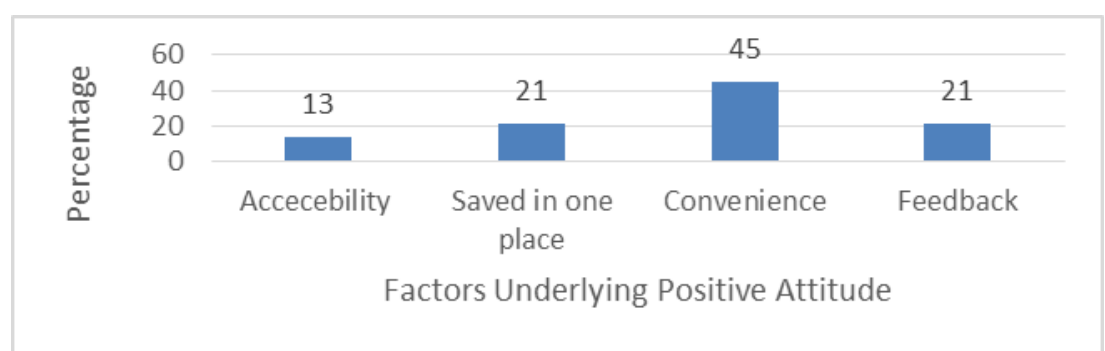

Figure 1

Factors underlying Learners' Positive Attitude

Analysis of the data indicated that the most important factors described by participants as reasons underlying their positive attitude toward e-portfolio fell within four categories: the e-portfolio accessibility, the fact that all their documents can be saved in one place, e-portfolio's convenience, and the feedback they could receive through it. The data indicate that these four themes were interactive and related.

\section{Learners' Negative Attitudes towards E-portfolio}

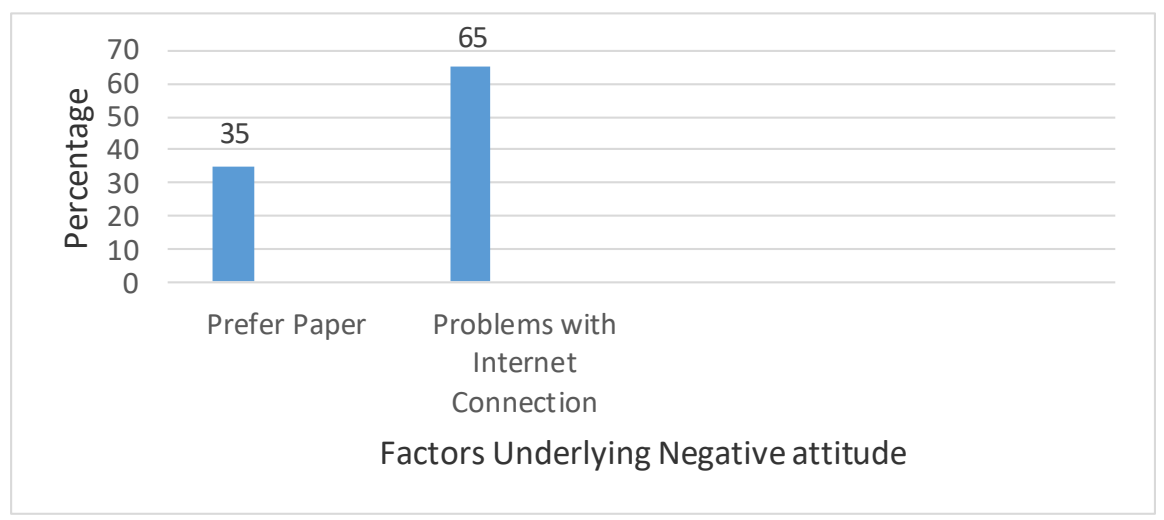

Figure 2

Factors underlying Learners' Negative Attitude

Data analysis showed that the most important factors described by participants as reasons causing their negative attitude toward e-portfolio fell within two categories; 
either they prefer traditional use of paper and pencil, or they experienced problems with Internet connection.

$65 \%$ of the learners who did not like using e-portfolios actually had experienced problems with Internet connection. It could be assumed that if they were provided with a better and stronger connection, their attitudes could change as well. In the meantime, having problems uploading their files or checking the feedback caused the negative attitude.

"This website is interesting to use if you have a computer and a strong Internet connection. Most of the time my internet connection was not good enough and as a result, I had problems uploading my assignment, or I missed the due-time."

$35 \%$ of the learners who hold a negative attitude towards EP mentioned that they simply prefer writing on a piece of paper rather than typing on a keyboard. Based on their educational experience, it seems quite understandable. Students in Iran do not participate in electronic classes or e-learning environments a lot, so this new experience had seemed hard to some of them.

"I prefer the usual method of writing on a paper. Maybe you call me oldfashioned, but that's just the way I am."

\section{Teacher's Field Notes and Unstructured Observations}

Despite learners' familiarity with the use of computers and the Internet, all of the learners asserted that they never had prior experience with e-portfolios in the educational setting. It was interesting to observe how learners helped each other with technological skills needed, especially during the beginning sessions of working with eportfolios. So in order to engage fully in the process of the writing class, learners shared ideas and tried helping each other with technological skills. As a result of learning from each other, learners' confidence has significantly increased during the semester. Based on the results of the open-ended survey, participants had developed four skills during the semester through using e-portfolios:

- Time management

- $\quad$ Typing and using the Internet

- $\quad$ E-learning/ E-class

- $\quad$ Self-discipline

\section{DISCUSSION AND CONCLUSION}

The evidence from one-semester long study indicated that the e-portfolio method had significant effects on the students' writing proficiency, while the conventional method did not have such effects on learners' writing. In line with this result, Masaeli and Chalak (2016), stated that employing electronic portfolios can be a good technique for language teachers to make writing more interesting to language learners. Furthermore, Mustafa (2011) proved that there is a significant relationship between the use of 
electronic portfolio as a technique of assessing writing and learners' performance in their writing homework and Chang et al. (2011) proved the effectiveness of electronic portfolios among language teachers as an assessment tool.

Students claimed that peer assessment provide better scope to share their ideas and build social skills (Brown, Irving \& Keegan, 2008). Exchanging information was one of our many goals which was reached through the features provided by Edmodo, students were able to add their comments and evaluations to the posted materials, which included samples of their fellow classmates' writing, articles related to different styles of academic writing, or open-ended questions which posed topics to be discussed in the follow-up sessions of their class. Besides, open-ended questions and polls were designed to help learners search for answers and construct their knowledge through both individual and group activities.

The effects of e-portfolio method was not limited to learners' writing proficiency, it actually affected their use of self-regulated learning strategies as well. At the beginning of the study, all learners were unfamiliar with the website, they were all new to the pedagogy, and to on-line learning; so they needed "more learning support and scaffolding" (Kaider et al, 2009, p.497). They asserted that they had no previous experience of working with Edmodo, neither had they experienced e-learning or eteaching methods before. We asked an expert to provide the students with both the necessary information and a contact address for the future reference and further questions. Moreover, whenever they encountered an obstacle, they could contact the instructor either through Edmodo itself or through her email address. One thing that needs to be mentioned is that students in the control group also had some improvements as a result of the writing lessons they received in through the conventional method, but such improvements did not seem significant while the improvements in the e-portfolio group are strongly significant. This findings are in line with what Cohen and Macaro (2007) stated: "instruction and training influences the quality of essays"(p.247 ). Furthermore, Glaser and Brunstein (2007) found that learners who were subject to an instruction focusing on composition strategies in conjunction with self-regulation procedures were able to write more complete and better stories than the students in the comparison conditions. One can logically realize that these factors have mutual effects on each other. On the other hand, previous studies (e.g. Graham, et al., 2005) maintain that the ability to self-regulate is correlated to higher levels of writing achievement.

The qualitative data, mostly based on the researcher's observation and triangulated with field notes and learners' quotes, also showed that even though student in the experimental group, either consciously or unconsciously, benefitted from use of SRL strategies, leaners in the control group were mostly complaining to the researcher/ teacher about how difficult writing seems to them and were unable to employ any strategies to help themselves. Leaners in the control group lacked the abilities to manage their assignments, did not benefit from instructor's comments and feedback and expressed negative attitudes towards writing. One of them mentioned: 
Writing tasks seem difficult and time-consuming to me. I always postpone them to the last minute and I keep making the same mistakes. It is just too hard to follow all the rules.

Also, students' attitudes were investigated towards e-portfolio and in general, they expressed positive attitudes towards EP. The results obtained from this study were in line with most of the studies in the literature (for example, Burch, 2000; Corwin, 2003; Nezakatgoo, 2005).

However, because of the limitations involved in the study (such as time limitation and number of the participants), the results of this study should be used with caution. To contextualize the aforementioned findings and implications, bear in mind that as Tavakoli and Tavakol (2018) stated "our students need a proficiency level that would sustain them for a lifetime and our hunch is that they never have achieved and never will achieve this required proficiency going through this educational system." (p.41) Teachers and instructors at all levels in Iran need to remember that they can take their students one step further by providing them an opportunity through which they can experience a learning situation above what has been presented to them in on the curriculum.

\section{REFERENCES}

Abrami, P. C., \& Aslan, O. (2007). The Student Learning Strategies Questionnaire. Montreal, QC: Centre for the Study of Learning \& Performance, Concordia University.

Ali, S.Y. (2005). An introduction to electronic portfolios in the language classroom. The Internet TESL Journal, 6. Retrieved from http://iteslj.org

Allan, D. (2004). Oxford Placement Test. Oxford: Oxford University Press.

Anson, Ch. M. (2000). Distant voices: Teaching and writing in a culture of technology. In K.B. Yancey (Ed.), Issues and trends in postsecondary English studies (pp. 167189). Urbana-Illinois: National Council of Teachers of English.

Arnold, J., \& Brown, D. (1999). Affect in Language Learning. Cambridge: CUP.

Avraamidou, L., \& Zembal-Saul, C. (2002). Making the Case for the Use of Web-based Portfolios in Support of Learning to Teach. The Journal of Interactive Online Learning, 1 (2).112-125.

Brown, G., Irving, E., \& Keegan, P., (2008). An introduction to educational assessment, measurement and evaluation. New Zealand: Pearson.

Burch, C.B. (2000). Inside the portfolio experience: The student's perspective. In K.B. Yancey (Ed.), Issues and trends in postsecondary English studies (pp. 148-164). Urbana-Illinois: National Council of Teachers of English.

Chandler, J. (2000). The efficacy of error correction for improvement in the accuracy of L2 student writing. Paper presented at the American Association for Applied Linguistics Conference, Vancouver, Canada. 
Chang, C. C., Tseng, K. H., Chou, P. N., \& Chen, Y. H. (2011). Reliability and Validity of Web-based Portfolio Peer Assessment: A Case Study for a Senior High School's Students Taking Computer Course, Computers \& Education, 57(1), 1306-1316. doi: 10.1016/j.compedu.2011.01.014.

Cohen, A., \& Macaro, E. (2007). Language Learner Strategies: Thirty Years of Research and Practice. Oxford: OUP.

Corwin, T. (2003). Electronic Portfolios. Campus-wide information systems, 20 (1), 3238.Retrieved from http://www.ingentaconnect.com/content/mcb/165/2003/00000020/00000001/art00004

Ferris, D. R., \& Helt, M. (2000, March). Was Truscott right? New evidence on the effects of error correction in L2 writing classes. Paper presented at the American Association of Applied Linguistics Conference, Vancouver, Canada.

Firoozzare, A. (2006). The effectiveness of alternative assessments and traditional methods. Unpublished master's thesis, Allame Tabataba'i University, Tehran, Iran.

Glaser, C., \& Brunstein, J. (2007). Improving Fourth Grade Students' Composition Skills: Effects of Strategy Instruction and Self-regulation Procedures, Journal of Educational Psychologhy, 99(2), 297- 310.

Godwin-Jones, R. (2008). Emerging technologies web-writing 2.0: Enabling, Documenting, and Assessing Writing Online, Language Learning and Technology, 12, 7-13. Retrieved from http://llt.msu.edu/vol12num2/emerging.pdf

Graham, S., Harris, K., \& Mason, L. (2005). Improving the Writing Performance, Knowledge, and Self efficacy of Struggling Young Writers: The effects of selfregulated Strategy development, Contemporary Educational psychology, 30, 207- 241.

Heidari, F. (2009). Alternative assessment procedures in Iranian EFL writing classes: The wash back effect and students' attitudes. Unpublished doctoral dissertation, Allame Tabataba'i University, Tehran, Iran.

Hirvela, A., \& Sweetland, Y.L. (2005). Two Case Studies of L2 Writers' Experiences across Learning-directed Portfolio Contexts., Assessing Writing, 10, 192-213.

Hyland, K. (2003). Second language writing. Cambridge: Cambridge University Press.

Kaider, F., Henschke, K., Richardson, J. \& Kelly, M. P. (2009). Designing blended learning spaces to maximize student learning in work integrated learning programs, Ascilite, Auckland, New Zealand, 496-505.

Kayashima, M. \& Inaba, A. (2003). How do computers help a learner to master selfregulation skill? Local Proceedings of the International Conference on Computer Support for Collaborative Learning (CSCL2003), Bergen, Norway, June 14-18, 2003, pp. 123-125. 
Lalande, J. F. (1982). Reducing Composition Errors: An Experiment, Modern Language Journal, 66, 140-149.

Levin, D. M., Azevedo, R., Winters, F. I. \& Cromley, J. G. (2004). How does a teacher scaffold students' self-regulated learning during a collaborative science inquiry investigation in GenScope. Paper presented at the Annual Conference of the American Educational Research Association, San Diego, CA. (pp. 196-201).

Lynch, R. \& Dembo, M. (2004). The Relationship between Self-regulation and Online Learning in a Blended Learning Context, International Review of Research in Open and Distance Learning. 10, 26-28.

Masaeli, N., \& Chalak, A. (2016). The Effect of Employing Electronic Portfolio on Iranian EFL Learners' Writing Skill, Journal of Language Teaching and Research, 7(4), 746-751. doi: http://dx.doi.org/10.17507/jltr.0704.15.

Miles, M. B. \& Huberman, A.M (1994). Qualitative data analysis: A source book of new methods. Beverly Hills: Sage.

Muslimi, F. (2015). The Effect of Using Portfolio on the Development of Students' English Business Writing and their Attitudes towards the Course at Sana'a Community College, International Journal of Applied Research, 1(10), 414-423.

Mustafa, A. A. M. (2011). The Impact of Electronic Assessment-driven Instruction on Preservice EFL Teachers' Quality Teaching, International Journal of Applied Educational Studies, 10(1), 18-35.

Nezakatgoo, B. (2005). The Effect of Writing and Assessing Portfolio on Final examination scores and mastering the mechanics of writing of EFL students. Unpublished master's thesis, Allame Tabataba'i University, Tehran, Iran.

Paris, S. \& Winograd, P. (2001) The role of self-regulated learning in contextual teaching: principles and practices for teacher preparation. Retrieved September $17^{\text {th }}$, 2017, from http://www.ciera.org/library/archive.

Patton, Q.M. (2002). Qualitative Research \& Evaluation Methods. Sage Publications.

Perry, N. E. \& Vandekamp, K. J. O. (2000). Creating Classroom Contexts that Support Young Children's Development of Self-regulated Learning, International Journal of Educational Research, 33, 821-843.

Pezeshki, M. (2010). A comparative study of e-portfolios, portfolios and conventional writing classes. Unpublished master's thesis, Allame Tabataba'i University, Tehran, Iran.

Rogers, D., \& Swan, K. (2004). Self-regulated Learning and Internet Search, Teachers College Record, 106 (9), 804-824.

Saldana, J. (2013). The Coding Manual for Qualitative Researchers. Los Angeles: SAGE Publications. 
Tavakoli, M., \& Tavakol, M. (2018). Problematizing EAP Education in Iran: A critical Ethnographic Study of Educational, Political, and Sociocultural Roots, Journal of English for Academic Purposes, 31, 28-43.

Woodward, H. \& Nanlohy, P. (2004). Digital Portfolio: Fact or Fashion?, Assessment \& Evaluation in Higher Education, 29 (2), 227-238.

Zimmerman, B. J. (1989). A social cognitive View of Self-Regulated Academic learning. Journal of Educational Psychology. 81, 3, 329-339.

Zimmerman, B. J. (2000). Attaining self-regulation: A social cognitive perspective. In M. Boekaerts, P. R. Pintrich, \& M. Zeidner (Eds.), Handbook of Self-Regulation (pp. 13-39). San Diego, CA: Academic Press.

Zimmerman, B.J. \& Risenberg, R. (1997). Becoming a Self-regulated Writer: A Social Cognitive Perspective, Contemporary Educational Psychology. 22 (1), 73-101.

Zhang, Sh. (2009). Has Portfolio Assessment Become Common Practice in EFL Classrooms? Empirical Studies from China, English Language Teaching, 2, 98-118. 